\title{
Difference between Neurodynamic Mobilization and Stretching Exercises for Chronic Discogenic Sciatica
}

\author{
HAYTHAM I. MORSI, M.Sc.; BASSEM G.D. EL NAHASS, Ph.D. and MONA M. IBRAHIM, Ph.D. \\ The Department of Physical Therapy for Musculoskeletal Disorders and its Surgery, Faculty of Physical Therapy, \\ Cairo University
}

\begin{abstract}
Background: Sciatica has noxious symptoms and critical functional disabilities, which disturbs people lives. Physiotherapy modalities play the most important role in the conservative management of sciatica.
\end{abstract}

Aim of Study: To compare the effectiveness of the slider, tensioner neurodynamic mobilization techniques and stretching exercises on pain intensity, range of motion (ROM) of ankle dorsiflexion, and functional disability in patients with chronic discogenic sciatica.

Patients and Methods: Thirty-six patients with unilateral chronic discogenic sciatica from both sexes, their ages ranged from 21-50 years, were randomly allocated into three equal groups. Group (A) received slider neurodynamic mobilization technique only, while group (B) received tensioner neurodynamic mobilization technique only, and group (C) received stretching exercises of back extensors, hamstrings and gastrocnemius muscles only. In addition to ergonomic advice given to all the three groups. Treatment was given three days per week for two consecutive weeks. The outcome measures were assessed pre and post treatment. Pain intensity was measured using visual analogue scale. ROM of ankle dorsiflexion was measured using the universal goniometer. Functional disability was measured using the Oswestry disability index.

Results: There were found significant differences in both; the slider and tensioner neurodynamic mobilization techniques as compared to stretching exercises in pain intensity and functional disability. There were found no significant differences between the three groups in ankle dorsiflexion ROM.

Conclusion: Slider and tensioner neurodynamic mobilization techniques are more effective than stretching exercises in terms of reducing pain intensity and improving functional disability without significant differences between them in improving ankle dorsiflexion ROM.

Key Words: Slider - Tensioner neurodynamic mobilization Stretching Exercises - Sciatica.

Correspondence to: Dr. Haytham I. Morsi, The Department of Physical Therapy for Musculoskeletal Disorders and its Surgery, Faculty of Physical Therapy, Cairo University

\section{Introduction}

LOW back pain (LBP) represents now the number one cause of disability in most of countries. Its costs are increasing especially in poor underdeveloped health-care and social systems [1]. Sciatica refers to a set of symptoms including pain, numbness, muscular weakness and limitations in moving or controlling legs due to compression and irritation of the sciatic nerve. Symptoms are usually found in the lower back, buttocks and several dermatomes of the leg and foot [2].

Prevalence of sciatica varies greatly between studies ranging from $1.6 \%-43 \%$ [3]. Sciatica affects females more than males and affects people with sedentary life style more than active ones [4]. It may appears either suddenly with physical activity or gradually, and in most cases it is unilateral [5]

Main causes of sciatica include disc bulge or herniation, lumbar canal stenosis, spondylolisthesis, trauma, piriformis syndrome, spinal tumors and obesity [6]. In about $90 \%$ of cases, sciatica results from sciatic nerve compression as a result of a herniated disc [7]. Sciatica may be accompanied by LBP of variable intensity, which is not a permanent feature. Increased pain with coughing, sneezing, straining, or other forms of the Valsalva manoeuvres greatly indicate a disc rupture [5].

History and clinical examination represent the greatest role for sciatica diagnosis. Magnetic resonance imaging (MRI) is the most important means of medical investigations; especially when there are red flags or if the patient will have an interventional treatment [8]. Sciatic symptoms can be distressing with a noxious effect on daily life and productivity. The patient should be reassured about 
his own concerns and fears. He must be shared with information about the sciatica natural course and symptoms relief over time. In addition, to develop a plan, the treatment options should be explained taking into consideration his preferences [9].

To get effective and speedy recovery, physiotherapy programs represent the best way in the management process of sciatica [10]. A recent study showed that physiotherapy along with medical intervention has better clinical outcomes than medical intervention alone for patients with sciatica regarding improving the overall quality of life [4]

Disc herniation results in compression of nerve root which causes blood flow hindering of it [11] The alteration of the nerve microcirculation results in pain and release of various inflammatory mediators [12] . Furthermore, there is block of neural conduction, edema and mechanical sensitization after nerve root compression [13]. Neurodynamic mobilization can greatly reduce inflammatory mediators and consequently pain of sciatic nerve compression [14]. Furthermore, stretching of the sciatic nerve after experimentally induced sciatica in rats results in reduction of intraneural edema and adhesions and finally recover nerve mechanosensitivity [15].

Neurodynamic mobilization plays a great role in restoring the neural tissue ability to stress or tension via inducing reconstruction of normal physiological functions, pain reductions, and functional improvement [16].

Regarding applying of neurodynamic mobilization techniques, as long as the disorder is chronic, with no acute episodes, stable neurological changes, and not related to any disease process, the neural tissue can be mobilized but with constant reevaluation to get results without any adverse events [17]. The slider neurodynamic mobilization technique produces sliding movement of the neural tissue in relation to its adjacent structures, which causes distribution of tension and compression along the nervous system instead of one specific region. On the other hand, the tensioner neurodynamic mobilization technique resembles a neurodynamic test, which produces tension in the neural tissue but without exceeding the tissue elastic capacity [18].

Stretching exercises represent a good treatment modality with a great therapeutic effect on pain and range of motion (ROM) limitations of a musculoskeletal origin. They should be applied in physiotherapy programs for treatment of chronic LBP [19].

For patients with discogenic sciatica, neurodynamic mobilization is very effective in reducing symptoms and limitations [20]. It has significant clinical outcomes regarding pain alleviation and restoring of sciatic nerve mobility [21,22]. After reviewing the available previous published studies, it was found that there is no previous study directly compared both techniques with stretching exercises in cases of chronic discogenic sciatica, although both techniques and exercises were found to induce good clinical outcomes when studied separately, so we will conduct this study to examine the superiority of effectiveness of them.

\section{Patients and Methods}

Study design and sample size calculation: This study was conducted at the outpatient clinics, faculty of physical therapy, Kafr Elsheikh University from September 2020 to March 2021. A clinical comparative study design was used for comparison between the effects of slider, tensioner neurodynamic mobilization techniques and stretching exercises for patients with chronic discogenic sciatica. Using G-power version 3.1.9.7 for windows to make a preliminary power analysis and regarding F-test study, alpha level of 0.05 , confidence interval $95 \%$ and effect size of 0.25 , the total sample size was 36 patient (twelve in each group).

Ethical statement: The current study was conducted in concordance with the international ethical standards and applicable local regulatory guidelines. A written informed consent was obtained from every patient before starting. The study's protocol was reviewed and approved by the Research Ethical Committee, Faculty of Physical Therapy, Cairo University, number (P.T.REC/012/002874).

Inclusion criteria: Patients were eligible for participation in our study if their age ranged between 21-50 years of both sexes. They were diagnosed by MRI confirming disc lesion. They have radicular pain duration for at least twelve weeks up to one year with no acute episodes in the last four weeks. Furthermore, they have positive slump test with reproduction of neurological symptoms. In addition, they have functional disabilities e.g. during lifting or walking.

Exclusion criteria: On the other hand, patients were excluded if they have sciatica due to other pathologies e.g. lumbar canal stenosis or piriformis syndrome. Patients after any spinal surgery e.g. unilateral hemilaminectomy or microdiscectomy. 
Patients with negative slump test. Progressive neurological symptoms e.g. hyperirritable and unstable symptoms. History of vertebral fracture or trauma. Systemic disorder e.g. diabetes mellitus. In addition, pregnant women.

Patients preparation and randomization:To reach the specific sample size, forty-seven patients were screened regarding the inclusion/exclusion criteria. To avoid selection bias, the patients were randomly allocated by simple random method by three unseen enveloped cards representing the three treatment groups. Group (A) received the slider neurodynamic mobilization technique only, while group (B) received the tensioner neurodynamic mobilization technique only, and group (C) received stretching exercises of back extensors, hamstrings and gastrocnemius muscles only. In addition to ergonomic advice given to all the three groups.

To provide safe and effective treatment, all interventions, evaluation and recording of all measurements pre and post-treatment were performed by the primary investigator (the same therapist). All the patients fitted the inclusion criteria, were given explanation of the treatment protocol in a simple language and they had the willing and the ability for participation in this study but after signing written consent forms.

\section{Clinical evaluation for patients recruitment:}

The slump test: It resembles the straight leg raising (SLR) test performed in sitting position combined with spinal flexion that induces more neural tension [23]. From sitting position on the edge of a plinth, asking the patient to slump forward flexing the thoracic and lumbar spine then asking him to flex his neck to get his chin on his chest. The therapist's hand is placed on the top of the patient's head and his elbow on the patient's thoracic spine maintaining this position. Then asking the patient to actively extend his knee and dorsiflex his ankle to reproduction of his pain/symptoms or until the end range. Finally, as a structural differentiation manoeuvre, the therapist removes his hand from the head of the patient and asks him to look up; if the neural tissue is affected, the symptoms will decrease [24]

\section{Assessment procedures:}

Measurement of pain intensity using the visual analogue scale (VAS): Asking the patient to put a horizontal mark on a continuous $10 \mathrm{~cm}$ line that represents his pain intensity, ranging from zero, which indicates no pain, or discomfort to 10 , which indicates the worst possible pain he could feel [25]
It has good validity and reliability for pain intensity measurement [26]

Measurement of ankle dorsiflexion ROM using the universal goniometer: From supine position and placing a roll under the knee in the goal to slacken the gastrocnemius muscle via flexing the knee $20^{\circ}$ to $30^{\circ}$; this position indicates the neutral position $0^{\circ}$. Then, placing the goniometer that will read $90^{\circ}$ indicating neutral position and passively dorsiflexing the ankle by approximating the dorsum of the foot to lower leg anteriorly. If the goniometer reads $70^{\circ}$, then the ankle dorsiflexion ROM is $20^{\circ}$ [27].

Measurement of functional disability using the Oswestry disability index - Arabic version: A simple and easy scale to understand and has high validity and reliability for assessment of functional disability [28]. Oswestry disability index (ODI) is a selfassessing questionnaire, which includes 10 items; each contains six levels of answers ranging from $0-5$. Its items include pain intensity, personal care, lifting objects, walking, sitting, standing, sleeping, sex life, social life, and travelling. A total score is calculated, divided by 50 and multiplied by 100 . It ranges between $0 \%$ indicating no disability to $100 \%$ indicating complete disability. Regarding interpretation of ODI based on scores: From 0 to $20 \%$ indicates minimal disability; from 20 to $40 \%$ moderate disability; from 40 to $60 \%$ : Severe disability; from 60 to $80 \%$ crippled and greater than 80\%: The patient has excessive incapacity [29].

Treatment procedures: The treatment protocol in each group was given three sessions per week for two weeks.

- The slider neurodynamic mobilization technique: In the slump position, the patient sits at the edge of the plinth with the thighs parallel to each other and arms crossing behind the back. Then asking the patient to move actively and conversely from a position of neck and trunk flexion, knee flexion, and ankle plantar flexion, to a position of neck and trunk extension, knee extension, and ankle dorsiflexion [18].

- The tensioner neurodynamic mobilization technique: In the slump position, the patient sits at the edge of the plinth with the thighs parallel to each other and arms crossing behind the back. Then asking the patient to move actively and conversely from a position of neck and trunk extension, knee flexion, and ankle plantar flexion, to a position of neck and trunk flexion, knee extension, and ankle dorsiflexion [18]. 
Both techniques (slider and tensioner) were provided three sets in every session; the first: 10 repetitions, while the second: 15 repetitions, and the third: 20 repetitions. The repetitions were gradually increased to assure patients' tolerance during the techniques. The end position was hold for 5 seconds and the rest between sets was 5 minutes.

\section{- Stretching exercises:}

Stretching of back extensor muscles: From cross sitting position, asking the patient to place his hands behind his neck adducting his scapulae and extending his thoracic spine to lock the thoracic vertebrae. Now, asking him to lean the thorax anteriorly onto the pelvis and flexing only at the lumbar spine. The therapist stabilizes the patient's pelvis via pulling back on the anterior-superior iliac spines [30].

Stretching of the hamstrings muscle: From long sitting position, with the patient's distal leg supported on a rolled towel, asking him to press down with his hands against the femur just above (not on) the patella which causes a sustained force to increase knee extension [23].

Stretching of the gastrocnemius muscle: From standing position on an inclined board with the patient's feet pointing upward and heels downward, asking him to lean forward so a greater stretch occurs as the body weight is on the heels. In this position, there is little stretch on the feet long arches. Little effort is needed to maintain this stretching position for extended periods [23].

Each muscle stretching was hold for 30 seconds, then a relaxing period of 30 seconds, three repetitions every session. In addition, one minute rest between stretching of each muscle.

-Ergonomic advice: It was given to each patient to help him live, work and sleep comfortably in the goal to eliminate reproduction of neurological symptoms.

A- Practice good posture; stand up erect without deviations.

B- Avoid sitting or standing for long time; take regular breaks for standing or walking around during work. Furthermore, put one foot on a footrest with switching your feet along work hours.

C- Maintain proper sleeping posture; minimize stress on your back via sleeping on one side or on your back with bending the knees slightly over a pillow.
D- Lift objects safely; make sure you lift anything from the squatting position.

E- Avoid wearing high heels; greater than $1 \frac{1}{2} 2$ inches high may predispose you to pain or injury due to body weight shifting anteriorly.

F- Do swimming regularly; to make your muscles strong as possible [6].

The therapist had given all patients written notes with pictures illustrating these advices as well.

\section{Statistical analysis:}

Demographic data of all patients in the three groups were collected and analyzed which included age, weight, height, body mass index (BMI), radicular pain duration, gender, and affected side. In addition, pre and post-treatment measurements of pain intensity (VAS), ankle dorsiflexion ROM, and functional disability (ODI).

The statistical package for social sciences (SPSS) version 26 for windows (Armonk, NY: IBM Corp) was used for data statistical analysis. Level of significance for all tests was set at $p$ value $<0.05$.

\section{Results}

Before analyzing the collected data, they were screened for all assumptions regarding the used tests for statistical analysis. For better presentation of results in text, tables, and figures, groups are named according to the treatment received.

Comparing the mean values of age, weight, height, BMI, and radicular pain duration for all patients in the three groups using one-way analysis of variance (ANOVA) test which revealed that there were no significant differences between them in age ( $p=0.59)$, weight $(p=0.45)$, height $(p=0.85)$, BMI ( $p=0.43)$, and radicular pain duration $(p=$ 0.76 ). In addition, gender and affected side distribution were tested using Chi-square test which revealed that there were no significant differences between the three groups for gender $(p=0.89)$, and affected side ( $p=0.43)$, Table (1).

Within group comparison of all variables in the three groups:

1- Pain intensity (VAS): Comparing the pre and post-treatment mean values using paired $t$-test for each group, there were found significant differences in the slider $\left(p=0.0001^{*}\right)$, tensioner $(p=0.0001 *)$, and stretching $(p=0.0001 *)$ groups. 
2- Ankle dorsiflexion ROM: Comparing the pre and post-treatment mean values using paired $t$ test for each group, there were found significant differences in the slider $(p=0.03 *)$, tensioner $\left(p=0.02^{*}\right)$, and stretching $\left(p=0.01^{*}\right)$ groups.

3- Functional disability (ODI): Comparing the pre and post-treatment mean values using paired $t$ test for each group, there were found significant differences in the slider $(p=0.0001 *)$, tensioner $\left(p=0.0001^{*}\right)$, and stretching $\left(\mathrm{p}=0.0001^{*}\right)$ groups.

Comparing the post-treatment mean values of all variables in the three groups using one-way ANOVA, there were found significant differences between the slider, tensioner, and stretching groups for pain intensity (VAS) $\left(p=0.002^{*}\right)$, and functional disability (ODI) $(p=0.0001 *)$. Regarding ankle dorsiflexion ROM, there were found no significant differences between the three groups $(p=0.37)$.

As for multiple comparisons between posttreatment mean values in the three groups, using post hoc tests (Tukey), there found significant differences in the slider group as compared to the stretching group in pain intensity and functional disability. In addition, there found significant differences in the tensioner group as compared to the stretching group in pain intensity and functional disability, Table (2).

Table (1): Demographic data in the three groups.

\begin{tabular}{|c|c|c|c|c|}
\hline \multirow{2}{*}{ Items } & \multicolumn{3}{|c|}{ Mean \pm SD } & \multirow{2}{*}{$\begin{array}{c}p- \\
\text { value }\end{array}$} \\
\hline & $\begin{array}{l}\text { Slider } \\
\text { group }\end{array}$ & $\begin{array}{l}\text { Tensioner } \\
\text { group }\end{array}$ & $\begin{array}{l}\text { Stretching } \\
\text { group }\end{array}$ & \\
\hline Age (years) & $\begin{array}{l}35.83 \pm \\
7.18\end{array}$ & $\begin{array}{l}32.92 \pm \\
7.33\end{array}$ & $\begin{array}{l}34.92 \pm \\
6.46\end{array}$ & 0.59 \\
\hline Weight (kg) & $\begin{array}{l}78.25 \pm \\
6.58\end{array}$ & $\begin{array}{l}78.92 \pm \\
5.92\end{array}$ & $\begin{array}{l}81.17 \pm \\
4.88\end{array}$ & 0.45 \\
\hline Height (cm) & $\begin{array}{l}170.83 \pm \\
7.33\end{array}$ & $\begin{array}{l}172.5 \pm \\
6.92\end{array}$ & $\begin{array}{l}171.25 \pm \\
7.79\end{array}$ & 0.85 \\
\hline BMI $\left(\mathrm{kg} / \mathrm{m}^{2}\right)$ & $\begin{array}{l}26.83 \pm \\
3.71\end{array}$ & $\begin{array}{l}26.42 \pm \\
1.93\end{array}$ & $\begin{array}{l}27.92 \pm \\
2.75\end{array}$ & 0.43 \\
\hline $\begin{array}{l}\text { Radicular pain } \\
\text { duration (months) }\end{array}$ & $\begin{array}{l}5.92 \pm \\
2.47\end{array}$ & $\begin{array}{l}6.17 \pm \\
2.69\end{array}$ & $\begin{array}{l}5.42 \pm \\
2.39\end{array}$ & 0.76 \\
\hline $\begin{array}{l}\text { Gender: } \\
\quad \text { Males }(\%) \\
\text { Females }(\%)\end{array}$ & $\begin{array}{l}5(41.7) \\
7(58.3)\end{array}$ & $\begin{array}{l}5(41.7) \\
7(58.3)\end{array}$ & $\begin{array}{l}4(33.3) \\
8(66.7)\end{array}$ & 0.89 \\
\hline $\begin{array}{l}\text { Affected side: } \\
\text { Right }(\%) \\
\text { Left }(\%)\end{array}$ & $\begin{array}{l}8(66.7) \\
4(33.3)\end{array}$ & $\begin{array}{l}9(75) \\
3(25)\end{array}$ & $\begin{array}{l}6(50) \\
6(50)\end{array}$ & 0.43 \\
\hline
\end{tabular}

Table (2): Multiple comparisons: Post hoc tests (Tukey).

\begin{tabular}{lll}
\hline Groups & $\begin{array}{c}\text { Mean } \\
\text { difference }\end{array}$ & $\begin{array}{c}p \text { - } \\
\text { value }\end{array}$ \\
\hline Pain intensity (VAS): & & \\
$\quad$ Slider - Tensioner group & -0.33 & 0.84 \\
$\quad \begin{array}{l}\text { Slider - Stretching group } \\
\text { Tensioner - Stretching group }\end{array}$ & -2.08 & $0.003^{*}$ \\
Functional disability (ODI): & & $0.01^{*}$ \\
$\quad$ Slider - Tensioner group & -3.08 & 0.14 \\
$\quad$ Slider - Stretching group & -10.08 & $0.0001^{*}$ \\
Tensioner - Stretching group & -7 & $0.0001^{*}$ \\
\hline VAS = Visual analogue scale. & $p$-value = Probability. \\
ODI = Oswestry disability index. & $*=$ Statistically significant.
\end{tabular}

\section{Discussion}

There were found that the slider and tensioner neurodynamic mobilization techniques are more effective compared to stretching exercises in reducing pain intensity and improving functional disability.

The current study results supported the effect of neurodynamic mobilization in the management process of discogenic sciatica concerning pain alleviation and restoring of sciatic nerve mobility. After nerve root compression and microcirculation compromised, the pressure on the nerve induces oedema and hypoxia. Neurodynamic mobilization techniques consist of short sustained movements which are effective in oedema dispersing and hypoxia alleviating in the goal to reduce the associated symptoms and dysfunctions [18]

The findings of this study may greatly be affected by the relation between the passage of the sciatic nerve and piriformis muscle. The sciatic nerve usually emerges from the greater sciatic foramen inferior to the piriformis muscle. In $12.2 \%$, it is divided before leaving the greater sciatic foramen; the common peroneal branch emerges through the piriformis muscle. In $0.5 \%$ of the studied cases, the common peroneal branch passes superior to the muscle [31]. This relation may greatly affect the severity of symptoms and the response to treatment as neurodynamic mobilization involves the ability of the nerve to move and glide in relation to the adjacent structures along its pathway.

Slider techniques are very effective in treatment of neural disorders in which the pain is the chief complain. This is because of inflammatory exudate removal and tissue oxygenation improvement, which results in restoring of the normal physiological status of the nerves. On the other hand, ten- 
sioner techniques are used to induce viscoelastic, movement related and physiological processes in the neural tissues. Tension is applied to the neural tissues via increasing the distance between both ends of the nerve, which results in elongating the nerves through the telescope containing them [18]

Slider techniques mobilize the nerve over their distal root while relieve it over their proximal attachment and vice versa. On the other hand, tensioner techniques farther mobilize the nerve over their proximal and distal attachment at the same time. Thus, slider techniques induces less nerve strain than tensioner techniques [32].

The findings of this study are in line with the results of the in vivo trial using ultrasound imaging conducted by Ellis et al., [33] who measured longitudinal sciatic nerve movement during the slider and tensioner neurodynamic mobilization techniques. He found that both techniques induce increase in sciatic nerve mobility and excursion with a more significant effect for the slider technique. Moksha et al., [34] compared the slider and tensioner neurodynamic mobilization techniques combined with home exercise program on 60 patient with non-specific low back pain (NSLBP) associated with radicular lower limb symptoms. He found that both techniques have better positive effects on reducing pain intensity, increasing hip flexion ROM, and improving functional disability with more significant effect for the slider neurodynamic mobilization technique in all outcome measures. The results differs from the findings of our study regarding the pain intensity and functional disability, which may be attributed to the delimitation of his sample to all NSLBP patients.

Regarding the ankle dorsiflexion ROM, there are no previous studies that applied any of the slider or tensioner neurodynamic mobilization techniques to measure their effect on increasing or not changing the joint range, so it is impossible to make a direct comparison of this study results with other studies.

\section{Conclusion:}

Slider and tensioner neurodynamic mobilization techniques are more effective than stretching exercises in terms of reducing pain intensity and improving functional disability in treatment of patients with chronic discogenic sciatica. Furthermore, both techniques and stretching exercises have no significant differences between each other in improving the ankle dorsiflexion ROM.

\section{References}

1- HARTVIGSEN J., HANCOCK M.J., KONGSTED A., LOUW Q., FERREIRA M.L., GENEVAY S., HOY D., KARPPINEN J., PRANSKY G., SIEPER J. and SMEETS R.J.: What low back pain is and why we need to pay attention. The Lancet. Jun., 9; 391: 2356-67, 2018.

2- SOLANKI H.R.: A Comparative Study to Determine the Effectiveness of Neural Tissue Mobilization v/s IFT for Sciatica. Website: www. ijpot. com . Oct., 9 (4): 142-5, 2015.

3- KONSTANTINOU K. and DUNN K.M.: Sciatica: Review of epidemiological studies and prevalence estimates. Spine. Oct., 15; 33 (22): 2464-72, 2008.

4- SALEEM M., IFTIKHAR S., JAVAID R., RANA T., RANA M. and ARFAT Y.: Sciatica: Medical treatment or Physiotherapy?. African Journal of Pharmacy and Pharmacology. Aug., 31; 13 (14): 203-12, 2019.

5- ROPPER A.H. and ZAFONTE R.D.: Sciatica. New England Journal of Medicine. Mar., 26; 372 (13): 1240-8, 2015.

6- KUMAR M., GARG G., SINGH L.R., SINGH T. and TYAGI L.K.: Epidemiology, pathophysiology and symptomatic treatment of sciatica: A review. Int. J. Pharm. Biol. Sci. Arch. Aug., 2 (4): 1050-61, 2011.

7- VALAT J.P., GENEVAY S., MARTY M., ROZENBERG S. and KOES B.: Sciatica. Best Practice and Research Clinical Rheumatology. Apr., 1; 24 (2): 241-52, 2010.

8- VAN BOXEM K., CHENG J., PATIJN J., VAN KLEEF M., LATASTER A., MEKHAIL N. and VAN ZUNDERT J.: 11. Lumbosacral radicular pain. Pain Practice. Jul., 10 (4): 339-58, 2010.

9- JENSEN R.K., KONGSTED A., KJAER P. and KOES B.: Diagnosis and treatment of sciatica. BMJ. Nov., 19; 367 (11): 1-6, 2019.

10- ADRIANA C. and NICOLETA M.M.: Effects of physical therapy in patients with sciatica. ARS Medica Tomitana. Nov., 1; 18 (4): 174-8, 2012.

11-KOBAYASHI S., SUZUKI Y., ASAI T. and YOSHIZAWA H.: Changes in nerve root motion and intraradicular blood flow during intraoperative femoral nerve stretch test: Report of four cases. Journal of Neurosurgery: Spine. Oct., 1; 99 (3): 298-305, 2003.

12- KOBAYASHI S., YOSHIZAWA H. and YAMADA S.: Pathology of lumbar nerve root compression Part 2: morphological and immunohistochemical changes of dorsal root ganglion. Journal of Orthopaedic Research. Jan., 22 (1): 180-88, 2004.

13- REMPEL D., DAHLIN L. and LUNDBORG G.: Pathophysiology of nerve compression syndromes: Response of peripheral nerves to loading. JBJS. Nov., 1; 81 (11): 1600-10, 1999.

14- SANTOS F.M., SILVA J.T., GIARDINI A.C., ROCHA P.A., ACHERMANN A.P., ALVES A.S., BRITTO L.R. and CHACUR M.: Neural mobilization reverses behavioral and cellular changes that characterize neuropathic pain in rats. Molecular pain. Jul., 29 (8): 1744-57, 2012.

15- BERTOLINI G.R., SILVA T.S., TRINDADE D.L., CIENA A.P. and CARVALHO A.R.: Neural mobilization and static stretching in an experimental sciatica model: An 
experimental study. Brazilian Journal of Physical Therapy. Dec., 13 (6): 493-8, 2009.

16- SHACKLOCK M.: Neurodynamics. Physiotherapy. Jan., 1; 81 (1): 9-16, 1995.

17- BUTLER D.S. and JONES M.A.: Mobilisation of the nervous system. $1^{\text {st }}$ ed. Elsevier health sciences. Singapore, Pp. 104, 1991.

18- SHACKLOCK M.: Clinical neurodynamics: A new system of neuromusculoskeletal treatment. 1 st ed. Elsevier Health Sciences. China, Pp. 2, 156, and 203, 2005.

19- ANGELOVA P.: Stretching as a part of a strategy for the prevention and management of chronic low back pain. Trakia Journal of Sciences. Sep., 2; 17 (1): 905-8, 2019.

20- SHAKER H.A. and ABD EL-MAGEED S.M.: Effect of Neurodynamic Mobilization on Chronic Discogenic Sciatica. Bulletin of Faculty of Physical Therapy, 13 (1): 153-61, 2008.

21- YAMIN F., MUSHARRAF H., REHMAN A.U. and AZIZ S.: Efficacy of Sciatic Nerve Mobilization in Lumbar Radiculopathy due to Prolapsed Intervertebral Disc. Indian Journal of Physiotherapy and Occupational Therapy-An International Journal. Jan., 10 (1): 37-41, 2016.

22- VARTAK H.S., RAJAPURKAR R., PALEKAR T., SAINI S. and KHISTY A.: A comparative study between neural mobilisation techniques versus nerve flossing technique in patients with acute sciatica, 9 (3): 909-22, 2019.

23- KISNER C., COLBY L.A. and BORSTAD J.: Therapeutic exercise: Foundations and techniques. 7 th ed. F. A. Davis Company. Philadelphia, USA, Pp. 83, 831, and 889, 2018.

24- PORTER S.: Tidy's Physiotherapy E-Book. 15 th ed. Elsevier Health Sciences. United Kingdom, Pp. 567, Jan 17, 2013.

25- CRELLIN D.J., HARRISON D., HUTCHINSON A., SCHUSTER T., SANTAMARIA N. and BABL F.E.: Procedural Pain Scale Evaluation (PROPoSE) study:
Protocol for an evaluation of the psychometric properties of behavioural pain scales for the assessment of procedural pain in infants and children aged 6-42 months. BMJ Open, Sep 1; 7 (9): 1-12, 2017.

26- BEGUM M.R.: Validity and Reliability of Visual Analogue Scale (Vas) For Pain Measurement. Journal of Medical Case Reports and Reviews, Nov. 8; 2 (11): 394-402, 2019.

27- CLARKSON H.M.: Musculoskeletal assessment. 3 rd ed Wolters Kluwer Health. Philadelphia, USA, Pp. 352, 2013.

28- RAMZY R.: Validation of the Arabic version of the Oswestry Disability Index developed in Tunisia for low back pain patients in the UAE (Doctoral dissertation, Stellenbosch: Stellenbosch University), 2008.

29- FAIRBANK J.C., COUPER J., DAVIES J.B. and O'BRIEN J.P.: The Oswestry low back pain disability questionnaire. Physiotherapy, Aug. 1; 66 (8): 271-73, 1980.

30- KISNER C. and COLBY L.A.: Therapeutic exercise: Foundations and techniques, 5 th ed. F. A. Davis Company. Philadelphia, USA, Pp. 447, 2007.

31- MOORE K.L. and DALLEY A.F.: Clinically oriented anatomy. Wolters Kluwer. China, Pp. 1677, Jul. 12, 2018.

32- COPPIETERS M.W. and BUTLER D.S.: Do 'sliders' slide and 'tensioners' tension? An analysis of neurodynamic techniques and considerations regarding their application. Manual therapy, Jun. 1; 13 (3): 213-21, 2008.

33- ELLIS R.F., HING W.A. and MCNAIR P.J.: Comparison of longitudinal sciatic nerve movement with different mobilization exercises: an in vivo study utilizing ultrasound imaging. Journal of orthopaedic and sports physical therapy, Aug. 42 (8): 667-75, 2012.

34- MOKSHA J., MEDHA D. and SWATI M.: Effectiveness of sliders vs tensioners on pain and disability in nonspecific low back pain with associated lower limb symptoms: A pretest posttest experimental study. IJHSR, 9 (9): 46-52, 2019. 


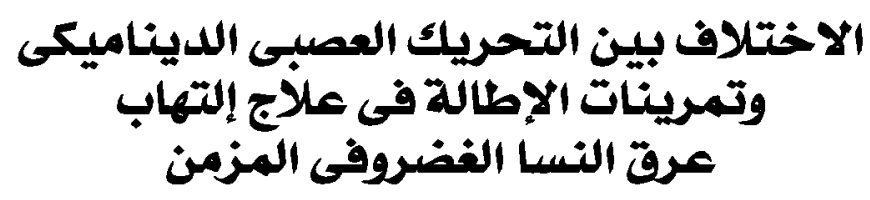

الخلفية: عرق النسا الفضروفى المزمن مشكلة صحية تصيب العديد من الأشخاص وينتج عنه أعراض مؤلمة وإعاقات مزعجة تؤثر على حياتهم.

الهدف: تهدف هذه الدراسة إلى المقارنة بين تأثيرات تقنيات التحريك الصصبى الديناميكى المنزلق والمتشدد وتمرينات الإطالة فى علاج إلتهاب عرق النسا الغضروفي المزمن.

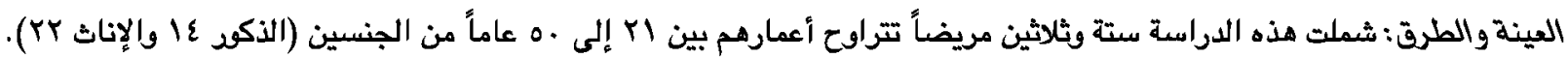

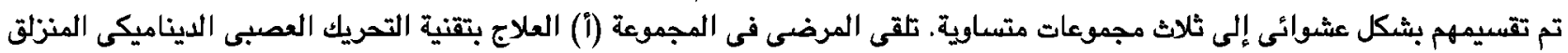

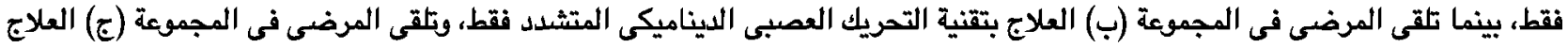

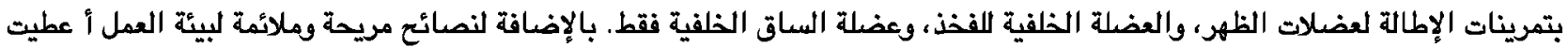

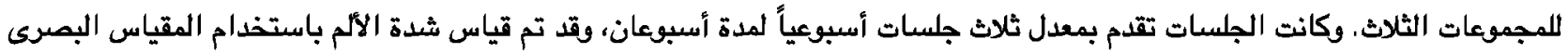

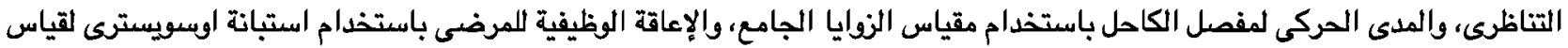
نسبة العجز، وذلك كله قبل بداية العلاج وفى نهايته.

النتائج:وجد تصسن وفروق ذات دلالة إحصائية بعد العلاج فى مجموعة التصريك العصبى الديناميكى المنزلق والمتشدد بالمقارنة مع مجموعة

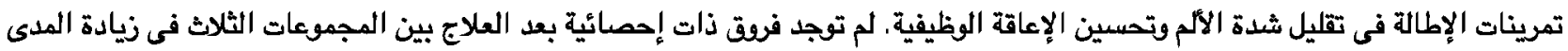
الصركى لمفصل الكاحل.

الخلاصة: تقنيتا التصريك العصبى الديناميكى المنزلق والمتشدد لهما تأثيراً أعلى من تمرينات الإطالة فى تقليل شدة الآلم وتصسين الإعاقة

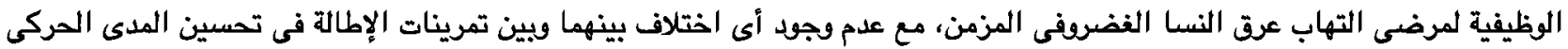
لمفصل الكاحل. 